from which the air has been exhausted and into which a small quantity of neon gas has been admitted. The current passes by discharge between two electrodes within the bulb, and consequently, as the heat capacity of the rarefied gas is practically negligible, it lights up and darkens to all intents and purposes instantaneously as the current is switched on and off. It is stated that as many as 10,000 distinct flashes per second can be obtained. A strong and efficient instrument has now been constructed to work with this lamp, the details of which will be found in the account of Dr. Crowley's paper in the Illuminating Engincer, Aug.-Sept., 1923. On the occasion of his lecture Dr. Crowley applied this apparatus to the study of the motions of the sewing machine. 'The vertical driving rods could be caused to appear at rest or moving very slowly, and the number marked on a small lever, actually in rapid vibration, could be read with ease. $\mathrm{Mr}$. Leon Gaster in his comments on the lecture points out that the device places a new weapon in the hands of the student of mechanics. It enables the operator actually to observe machinery in rapid movement as if it were stationtary, and so to recognize and correct defective action before it has revealed itself by spoilt work. The phenomenon of "persistence of vision," on which the instrument depends is also utilized to a certain extent in the kinematograph with, however, the important difference that with the oscilloscope the movements are seen while actually taking place and not, as with the kinematograph, recorded afterwards. A photograph of a milling cutter revolving at 125 revolutions per minute with a cam revolving at 250 revolutions per minute, together with a photograph of the same apparatus at rest, the former being taken by the light of the oscilloscope lamp, is used to illustrate the paper. Mr. Gaster points out that many other mechanical problems hitherto only treated theoretically, such as the whirling of shafts, the vibrations of unbalanced machinery, and the results of inaccurately fitting bearings, may be studied with the help of such apparatus from a more practical standpoint.

\title{
The Middlemore Lecture, 1923
}

This annual lecture was delivered last year by Mr. N. C. Ridley of Leicester, on ophthalmology and general practice, with the evolution of the former, and was published in the Midland Medical Journal.

It is good for the ophthalmic surgeon to unbend at times, to change from his scientific or clinical outlook and to wander for a few moments into the bypaths of the history of his subject. The origin of ophthalmology is hidden in the mists of remote antiquity : 
probably, as Mr. Ridley says, the demand for eye doctors created the supply. We know how large a part diseases of the eye formed in all the old treatises and it needs no very deep knowledge of the Bible to be aware of the fact that blindness is often referred to, while everyone remembers the miraculous restoration of sight recorded in the New Testament, where the miracle "was probably chosen as unassailable evidence of supreme power over evil, for it would be looked upon as almost as great a thing as the raising of the dead."

The legitimate practitioner and the quack must have arisen almost simultaneously; they grew up side by side and they are flourishing to-day. Mr. Ridley's fascinating lecture dealt with - many subjects of interest, ranging from the evil eye, Greco-Roman medicaments and ophthalmology 200 years ago to spectacles, opticians and the ophthalmoscope, fees and the general practitioner, and it was illustrated by 27 lantern slides. With such a wealth of material on which to draw, it is not surprising that the lecture is not only valuable to the archaeologist but also extremely interesting to the ordinary medical mind. We have not sufficient space in which to abstract it fully, but we may be pardoned if we attempt to elaborate a little one of the many subjects on which the author touched, that of the Roman oculist's stamps.

It is a remarkable thing that so many of these have been discovered, not only on the Continent, but even in the outlying province of Britain. Hardly a Roman site of any importance that has been excavated during the last century but has yielded one of these objects, and the names engraved on them are never the same. Mr. Ridley mentions the one in the Leicester (Ratae) Museum which was the property of Gaius (should this be Caius?) Pal Gracilis, but there are many others, such as the Kenchester (Magna) stamp, the Wroxeter (Viroconium) stamp found in 1808, that found at Cirencester (Corinium) which belonged to Minervalis, that of Titus Junianus of Bath (Aquae Solis) found in 1731 and, among others, that found at Gloucester (Glevum).

These stamps are usually square or rectangular blocks of stone with the inscription cut on the edges, but two, the Leicester and Wroxeter stamps are circular, and in the case of the latter, the inscription is cut on the face; they were doubtless used to impress the maker's name and the directions for use on the ointment; much as the maker's name is impressed on the modern cake of soap. For the most part the Roman collyrium or dialebanum was described as a specific for all diseases of the eyes, to be used "ex ovo," with egg, but at times more precise information was given, such as "ad claritatem," for clearness of vision; the golden collyrium for clearness of vision; for old cicatrices, and the dialebanum against blear eye "lippitudo, etc." 
We hope that Mr. Ridley's scholarly article will be read by all ophthalmic surgeons; Middlemore himself was keenly interested in the history of medicine, and it is a subject that none of us can afford to overlook.

\section{ABSTRACTS}

\section{I.-PERIMETRY AND VISUAL FIELDS}

\section{Hill, Emory. - Cases of bitemporal contraction of the visual}

fields. Amer. Jl. of Ophthal., Vol. VI, No. 4, April, 1923.

The author contributes a paper based on forty cases seen in the past three years, which presented fields indicating pressure on the chiasma. He discusses the cases under the following headings: Hypopituitarism; recurrent convulsions with hypopituitarism; pituitary headache ; pituitary disturbances in relation to infections; hyperpituitarism ; cerebral syphilis; hydrocephalus, and tumours. Under pituitary headache, he points out that such cases are for the most part hypopituitarism, with headache as the most conspicuous symptom: the headache is deep seated in the temporal regions. His cases of hypopituitarism, twenty-seven in number, gave a history of headache in seventeen; nine of these confessed to bitemporal pains, and of the nine, six had epileptiform attacks and in three of these six the attacks were associated with severe bitemporal pains. Such cases have slight bitemporal contraction of the fields, with the characteristic upper temporal slants. Three illustrative cases of pituitary headache are described.

In his conclusions, the author dwells on the value of perimetry in the early diagnosis of slighter disorders situated in the region of the chiasma, and on the secondary effects caused by hydrocephalus. Large test objects are useless to bring out the finer changes in the fields ; the use of very small white or coloured test objects is urged; these often reveal tendencies towards bitemporal hemianopia. Enlargements of the blind spots, relative scotomata in the upper temporal quadrants and blurred temporal peripheries in which a large white disc is not recognised as white, but merely as a moving object have been specially frequent in his series of cases and these deserve special mention as precursors of temporal hemianopia.

R. R. J. 